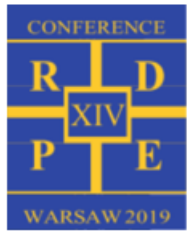

\title{
Experimental investigation of PWR accident scenarios at the PKL test facility
}

\author{
Rafat $\mathrm{B} \mathrm{ryk}^{1,2^{*}}$, Lars Dennhardt ${ }^{2}$ and Simon Schollenberger ${ }^{2}$ \\ ${ }^{1}$ Institute of H eat Engineering, W arsaw University of Technology, N ow owiejska 21/25, 00-665 W arsaw, Poland \\ 2 Framatome G mbH, Paul-Gossen-Straße 100, 91052 Erlangen, rafal.bryk@ framatome.com, Germany
}

\begin{abstract}
PKL is the only test facility in Europe that replicates the entire primary side and the most important parts of the secondary side of western-type Pressurized Water Reactors (PWR) in the scale of $1: 1$ in heights. It is also worldwide the only test facility with 4 identical reactor coolant loops arranged symmetrically around the Reactor Pressure Vessel (RPV) for simulation of nonsymmetrical boundary conditions between the reactor loops. Thermal-hydraulic phenomena observed in PWRs are simulated in the PKL test facility for over 40 years. The analyses carried out in these years encompass a large spectrum of accident scenario simulations and corresponding cool-down procedures. The overall goal of the PKL experiments is to show that under accident conditions - even for extreme and highly unlikely assumptions as additional loss of safety systems - the core cooling can be maintained or re-established by automatic or operatorperformed procedures and that a severe accident e.g. a core melt-down can be avoided under all circumstances. Another goal of the tests performed in the PKL facility is the provision of data for validation of thermal-hydraulic system codes. This paper presents recent modifications of the PKL facility, applied in order to adapt the facility to the latest western-type designs currently built in the world. The paper discusses also important results obtained in the last years.
\end{abstract}

\section{Introduction}

PKL is the German abbreviation for Primary Side Circuit. For over 40 years, since the construction of the PKL test facility, various test scenarios have always been reflecting safety issues addressed in the debate of the nuclear community at the international level. There are four general objectives of all campaigns conducted thus far:

- Investigation of thermal-hydraulic system behavior under accident situations

- Demonstration of safety margins

- Training of nuclear power plant (NPP) operation personnel

- Provision of data for thermal-hydraulic codes validation

During the years the focus of the nuclear community was evolving, so were the issues investigated at the PKL facility. Over 200 integral tests performed to date have contributed to a deeper understanding of sometimes highly complex phenomena occurring in different accident scenarios and to a better assessment of countermeasures implemented for emergency control.

The first test at the PKL facility was performed in 1977. Since then specific objectives of various tests were changing and so was the test facility itself. The test rig has been refitted several times to suite additional and ongoing tasks and to follow the latest developments in the fields of measuring instrumentation, data processing and new reactor designs. Such a modification of the PKL facility has been introduced in the course of the currently conducted test campaign - PKL III i. The main target of the implemented changes was a better replication of currently built American- and French-type PWRs. Before the modification PKL facility was strictly replicating German KONVOI PWR. Nowadays, all configurations are possible.

\section{PKL test programs}

At the very beginning of the PKL test facility operation i.e. in the seventies, the Large Break (LB) Loss of Coolant Accident (LOCA) was the design-basis accident for the emergency core cooling systems based on the Maximum Credible Accident (MCA) concept. Thus, the first test campaign was focused on verification of the effectiveness of the emergency core cooling systems (ECCS) adapted for controlling such events. Applying conservative assumptions, the very first test was conducted in 1977.

The first LB-LOCA test campaign was interrupted in 1979 by the accident in Three Mile Island unit 2 (TMI2 ). The small break (SB) LOCA which occurred in TMI2 directed the interest of the nuclear community to this kind of events. Therefore, shortly after the accident the PKL facility was adapted for simulation of the small breaks. Consequently, the TMI-2 scenario was replicated with the main focus on the safety margins demonstration of the operating units. As a result the LB- and SB-LOCA scenarios were covered within the test programs PKL I and PKL II $[1,2]$. 
After the completion of the PKL II, the next PKL III program was initiated in 1986. The goal of the subsequent project was the investigation of so-called accident transients with and without LOCA. The first test campaign of PKL III was focused on design-basis accidents and cool-down procedures specified in the operating manual. Progress in the field of probabilistic safety analyses then yielded values for the so-called integral Core Damage Frequency (CDF) for beyonddesign-basis accidents. To reduce the CDF for the beyond-design-basis accidents, preventive accident management $(\mathrm{AM})$ procedures were designed and tested at the PKL facility [3]. Typical topics of investigation studied within the test campaigns PKL III A to PKL III $\mathrm{D}$ are shown in the figure 1 [4].

In 1998 the Senior Group of Experts on Nuclear Safety Research Facilities and Programmes (SESAR/FAP) of the OECD/NEA Committee on Safety of Nuclear Installations (CSNI) presented a first set of results which not only comprised general and strategic recommendations but also proposed actions for immediate or near-term implementation. The safeguarding of integral test facilities for studying thermal-hydraulic issues was one of the actions assigned top priorities, provided test programs with unquestionable scientific interest are proposed. At its annual meeting in December 1999, the CSNI issued the recommendation to set up an international collaborative project in the field of thermal-hydraulics to implement the instruction made to this effect by SESAR/FAP. Based on programs, time schedules and cost offered by the various companies operating the test facilities, a proposal for a project called OECD/SETH (SESAR Thermal-Hydraulics) was elaborated. The project formulation was performed in consultation with the NEA Secretariat and it was submitted to the member countries in 2000. The proposal, which was based on experiments to be conducted in the PANDA and PKL test facilities, was approved by the project partners within OECD/NEA.
From the beginning of 2001 within the context of the OECD/SETH [6, 7] and OECD/PKL-programs [8] questions were examined in connection with inherent boron dilution [9], both after the SB-LOCA and accidents in cold shut-down condition (failure of residual heat removal system (RHRS) [10]), in particular with regard to the general sequence of events under various primary- and secondary-side boundary conditions.

Meanwhile, operational aspects of the scenario accidents in cold shut-down condition such as e.g. an optimization of procedures for troubleshooting in cold shut-down condition with regard to system use and return to safe RHR-operation were also focused on in the examinations. This scenario formed a main target of the OECD/PKL-2 program [11] that began in 2008. In the frames of the program the PKL III G tests campaign was conducted which additionally covered the topics indicated in the figure 1 [5].

Following the PKL III G tests campaign, the PKL III $\mathrm{H}$ test series was initiated in the framework of the OECD/PKL-3 program in April 2012. As the answer to open questions in the field of reactor safety - in particular as a contribution to the discussion related to the safety assessment of PWR in connection with the events in Fukushima 2011 - experimental investigations on the system behavior of PWR under beyond-designbasis accident scenarios (Station Blackout (SBO), LOCA with additional system failures) with a significant core heat-up were the central topics of the OECD/PKL-3 project [12]. The whole PKL III H tests campaign in the frames of the OECD/PKL-3 project covered the subjects depicted in the figure 1.

After completion of the PKL III $\mathrm{H}$ tests campaign, PKL III i program was proposed in the framework of OECD/PKL-4 project. The project was started in June 2016 and its goal is to address still open questions/topics that could not be covered within the previous investigations. It focuses on the parametric studies on the thermal-hydraulic procedures for the development and validation of the system codes and on the experimental

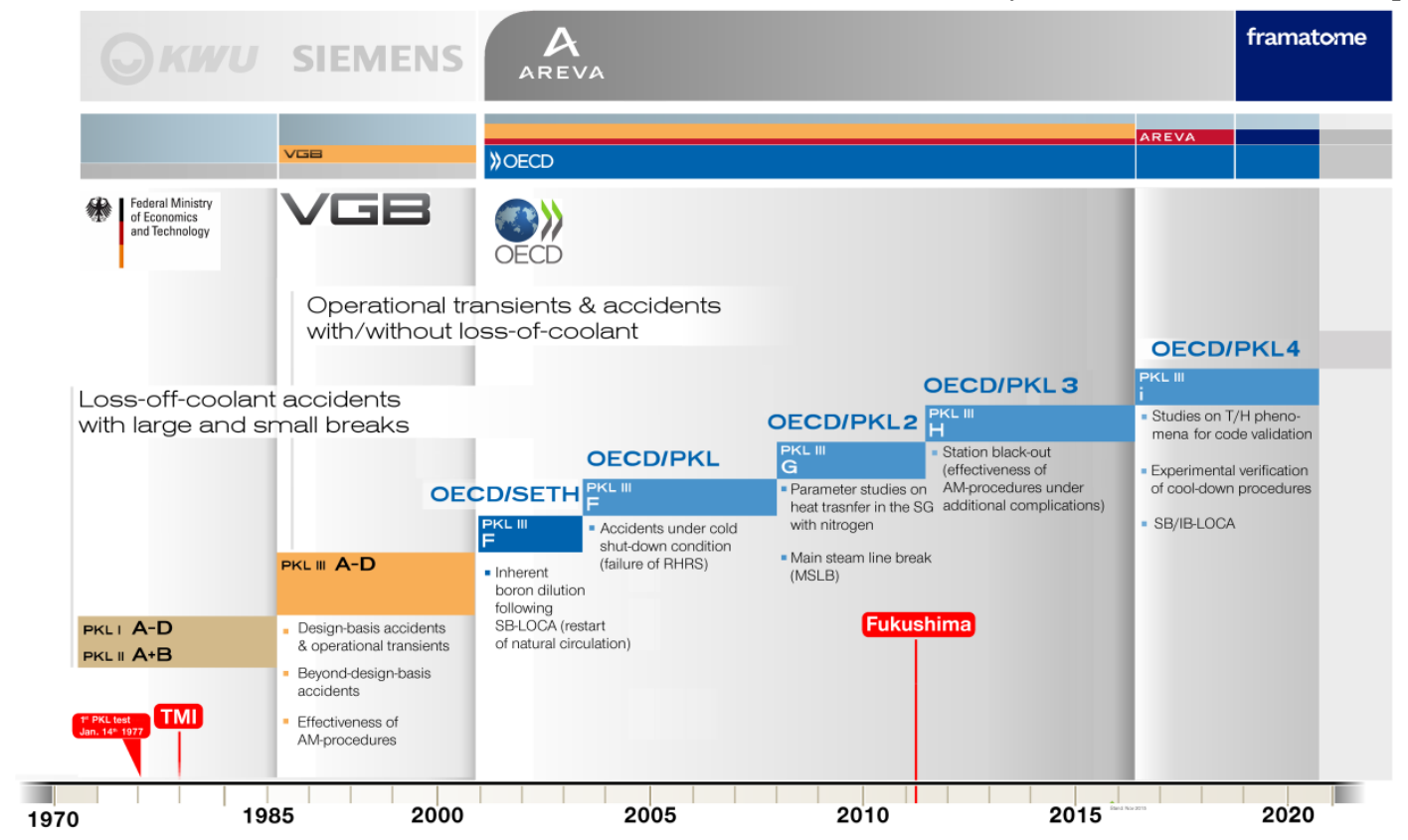

Fig. 1. PK L test programs 
verification of the cool-down procedures and operation modes for different incidents and accidents (figure 1) [13].

The OECD/PKL-4 project will be conducted until June 2020 .

\section{PKL description}

The PKL test facility models the nuclear steam supply system of a 1300 MWe nuclear power plant in a scale of 1:145. Detailed design was based to the largest possible extent on the Vorkonvoi type plant and on the specific data of Philippsburg nuclear power plant, unit 2. The facility replicates the entire primary side and the most relevant parts (excluding turbine and condenser) of the secondary side. As for the other test facilities of this size, the scaling concept aims to simulate overall thermalhydraulic behavior of the full-scale power plant. For this reason all geodetic heights are represented in 1:1 ratio. Power as well as volume and cross-sectional areas are replicated in 1:145 scales, which correspond to a hydraulic diameter reduction of 1:12. The single-phase pressure losses correspond to a large extent to the values in the PWR. Together with the heat losses they have been determined in detail for single components and for both, entire load and temperature ranges i.e. during RCPs in operation, NC-conditions and under hot and cold conditions [5].
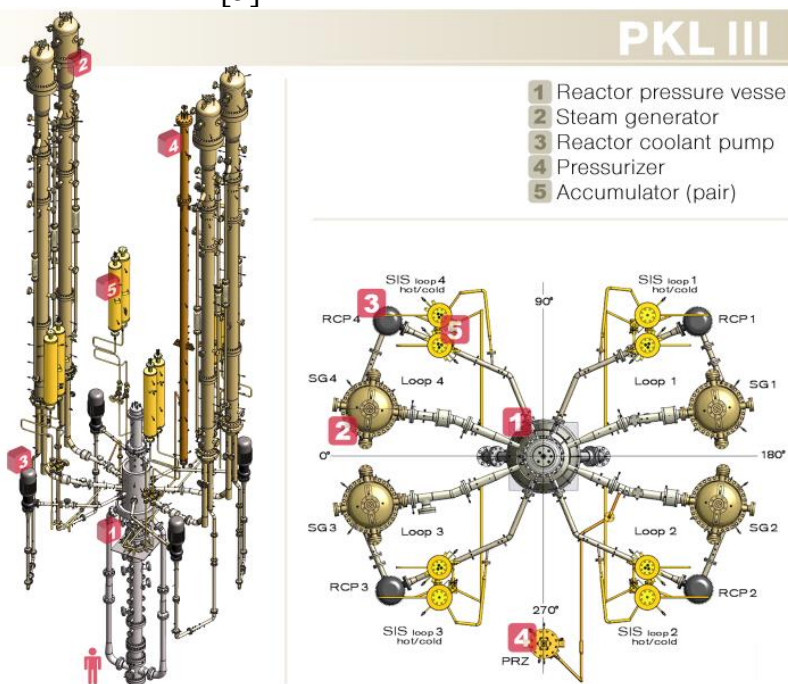

Fig. 2. PKL test facility

The Reactor Cooling System (RCS) comprises a rod bundle vessel containing a heater bundle (simulation of the reactor core), four loops with the reactor cooling pumps, steam generators, a downcomer model and a pressurizer. The pressurizer is connected to the RCS with a surge line.

The rod bundle vessel is a pressure vessel assembled from several elements and instrumentation rings. The whole vessel models the upper head (UH), upper plenum (UP), reactor core sections, reflector gap and the lower plenum.

The core is replicated as a section of the actual system. This means that the full-scale rod dimensions and spacers are used. However, the number of rods in the core is scaled down. Thus, the core is represented by 314 electrically heated rods with a total power of $2.5 \mathrm{MW}$ corresponding to $10 \%$ of the scaled-down nominal power. The PKL heater rod bundle has a uniform axial power profile and the rods are arranged in three concentric zones which are heated independently from one another. This enables the simulation of radial power profiles across the test bundle. The reflector gap between the rod bundle vessel and the bundle wrapper is modelled volumetrically to scale.

The RPV downcomer is replicated as an annulus in the upper region and as two stand pipes connected to the lower plenum. This configuration enables a symmetrical connection of the 4 cold legs (CL) to the RPV, a reliable determination of flow rates, a preservation of frictional pressure losses, and it does not unacceptably distort the volume/surface ratio. This is of importance with respect of the removal of stored heat from the walls during a cool-down procedure [5].

The upper head bypass is modelled by four parallel bypass lines associated with the respective loops to enable the detection of asymmetric flow phenomena in the RCS (e.g. single-loop operation). The replication of the bypass loss is provided by the installation of an appropriately scaled orifice in each bypass line.

The four SGs of the PKL facility are vertical U-tube bundle heat exchangers like their counterparts in the modelled nuclear power plant. The tube bundle is welded into the tube sheet. The cylindrical primary channel head located at the bottom is extended downward by two pipes, split into an inlet and an outlet plenum and flanged to the tube sheet above. The heat exchange surface in modelled to scale. Similarly to the reactor core rods, the SG U-tubes were modelled in the full-scale geometry with a reduced number of tubes according to the scaling principle of 1:145 with respect to the reference plant. Each of the four SGs is equipped with a separate main steam, feedwater, emergency feedwater and steam generator blowdown system.

The symmetrical arrangement of the 4 loops around the RPV also allows investigating individual effects of multiple system failures. Tests on the behavior of a 3loop or a 2-loop plant can also be conducted by isolating one or two loops of the PKL facility. Each of the primary side loops contains an active reactor coolant pump (RCP), which is equipped with a speed controller to enable the simulation of various pump characteristics [5].

The PKL facility is also equipped with all relevant safety and operational systems on the primary and secondary side. On the primary side, four independent high and low pressure safety injection (HPSI and LPSI) systems are connected to both, the hot and cold legs. Furthermore, the RHRS, 8 accumulators (ACC), the pressurizer (PRZ) pressure control system and the chemical and volume control system (CVCS) are replicated at the facility.

On the secondary side the feedwater system, the emergency feedwater system and the main steam lines with all control features of the original designs are reproduced. For the realistic illustration of the events during secondary side bleed-and-feed operations, the complex geometry of the feedwater system was 
modelled according to the scaling principle with the possibility of setting the corresponding temperature distributions. All these characteristics allow for the simulation of a wide spectrum of accident scenarios including the interaction between the primary and secondary side in combination with various safety and operational systems [5].

The PKL facility is extensively instrumented with around 2000 measurement points. This enables the accurate analysis and correct interpretation of the phenomena occurring during the tests. Apart from conventional measurements (temperature, pressure), two-phase flow and boron concentration measurement instrumentation are installed at the facility.

\section{PKL recent modifications}

In principle all western type PWRs have similar Reactor Vessel Internals (RVI) and they differ only in several aspects. Some of these design differences can have, however, a significant influence on both, the reactor normal and accidental operating states. An example of important design diversity is the Upper Support Plate (USP) which is installed in some reactor designs and it is not in others. The USP is a rigid base that positions and supports the control rod guide tubes and the upper support columns that in turn position and uphold the Upper Core Plate (UCP). The USP also directs the thermocouple columns and guides.

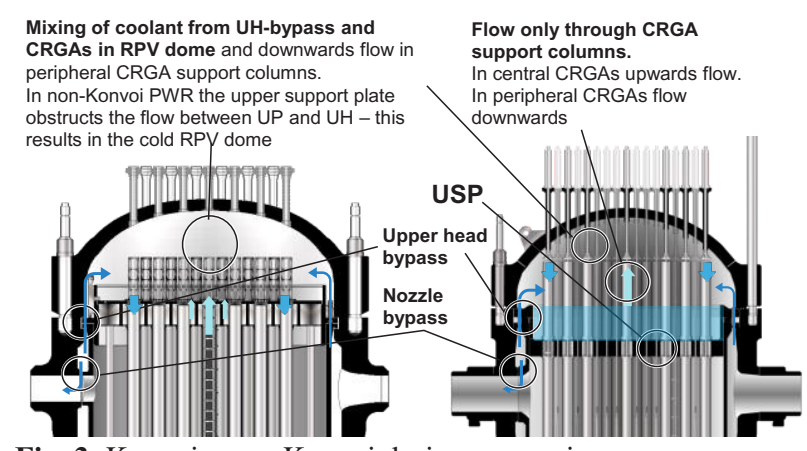

Fig. 3. Konvoi - non-K onvoi design comparison

The USP embedded between the UP and UH in the non-Konvoi design precludes free flow between the chambers and this has a significant influence on the operation of the reactor regardless of the operation mode. Figure 3 shows for instance liquid flows in the RPV during normal operation of the reactor. Under these conditions in the Konvoi reactor the water can freely flow between the UH and UP across practically the whole cross sectional area of the reactor (excluding the top plate area). In case of the non-Konvoi design the free flow is precluded and it is only possible through the control rod guide assemblies (CRGA), which in total strongly limit the flow area. Due to the limited direct flow from the UP to the UH the part of the indirect cold flow from the downcomer to the $\mathrm{UH}$ through the UH bypass is relatively bigger. This in turn results in lower temperature in the $\mathrm{UH}$ (so called cold dome configuration).
In case of the anomalous operation, for instance due to Loss of Offsite Power (LOOP) and resulting Natural Circulation (NC) the flow through the UH bypass would be reversed as a result of reversion of the pressure difference between the UH and the downcomer vessel. A so called sweeping flow would appear in the bypass due to the pressure difference. Further proceeding of the incident and application of the cool-down procedure i.e. depressurization of the RPV leads to flash boiling in the RPV being a reason for void formation. Flash boiling starts first in the hottest fluid volumes in the RCS which, for the Konvoi design, is usually the RPV dome. Consequently, the void would be collected in the UH of the RPV. In case of the non-Konvoi design it is likely that a void bubble would also appear below the USP resulting in the formation of two bubbles - one below the dome and one below the USP. The differences between the Konvoi and non-Konvoi designs are hence significant and they lead to meaningful discrepancies for certain operational and accident procedures.

In order to enable a simulation of the phenomena in the reactors of all types, the PKL facility was modified correspondingly to the non-Konvoi design. Figure 4 shows a comparison between the old and the new configuration of the facility.

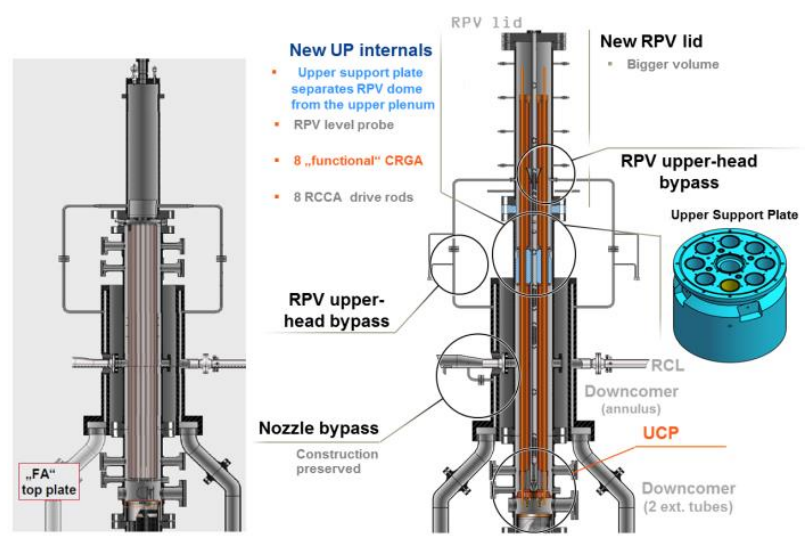

Fig. 4. PK L facility before and after modification

Due to the significant differences between the reference plants, replication of the non-Konvoi design by the PKL facility required substantial modifications. On the left side of the figure 4 there is a cross section through the PKL test facility before the modification. The UP and UH are basically two vessels separated by the top plate. The UH is practically empty while the UH houses filler tubes which serve for the correct replication of the volume/surface ratio of the facility. The pressure drop of the flow between the vessels is mainly simulated by the top plate which replicates the Konvoi design.

On the right side of the figure 4 the modified PKL facility is illustrated. Similarly to the non-Konvoi reference plant (EPR) the UH and the UP are separated by the USP. In the UP apart from the filler tubes there are also CRGA tubes with Rod Cluster Control Assemblies (RCCA) inside. The CRGAs are bolted to the UCP. They get through the USP and their top ends are in the UH. In the PKL facility, the pressure drop of the flow between the UP and UP is mainly simulated by 
the top caps of the CRGAs. The illustration on the right side of the figure 4 shows also a 3D picture of the USP. The component has thus 8 concentric holes for the CRGAs and one in the middle for the RPV water level measurement instrumentation.

An important feature of conducted modification is the possibility of exchanging the configurations. Therefore, after the adaptation of the facility to the nonKonvoi design, the original reference plant (and hence all the other designs which do not employ the USP) can still be simulated in the PKL test facility.

\section{Test results}

The total number of integral tests conducted at the PKL exceeds 200. Therefore, only a representative group of various tests can be presented.

\subsection{Heat transfer in the SG with failure of RHRS under $3 / 4$ loop operation}

Loss of residual heat removal system under shutdown conditions i.e. during mid-loop operation has occurred several times world-wide [14]. Increasing attention has been devoted to such incidents as various probabilistic safety assessments have shown that the contribution of these accidents accounts for $18 \%$ of the integral core damage frequency of $1.1 \times 10^{-5}$ per reactor per year and it is much larger than originally anticipated.

Various tests on loss of residual heat removal in midloop operation have already been included in the previous PKL test programs, some with the reactor coolant system closed and some with it (partially) open. Tests performed with the reactor coolant system closed showed that residual heat removal is assured if at least one steam generator is still operable. However, these test results also show that under certain boundary conditions, especially with only one SG operable, the cold-leg boron concentration can be significantly reduced in the long term. Furthermore, the test results suggest that boron dilution in the cold leg can be prevented if more than one steam generator is operable.
The test results also demonstrate, that under certain circumstances, the additional injection of water into the reactor coolant system (e.g. by the accumulators) can lead to a degradation of the heat transfer in the steam generators and thereby even hinder the reactivation of the RHR system (assuming that operability has been restored). The experiments revealed that the flow phenomena connected with heat removal and boron dilution are highly sensitive to slight changes in the boundary conditions. Possible scenarios and their expected influence on the system are presented in the figure 5 .

For further investigation of the phenomena occurring during RHRS failure a succeeding tests series was conducted. The following campaign was intended to provide a systematic analysis of the highly complex thermal hydraulic processes that occur in the SGs in the presence of nitrogen, steam and water, and to analyze the phenomena related to boron dilution and heat transfer to the secondary side. In the framework of the test campaign two tests were performed: one with a single SG under operation and the second one with two SGs available. Furthermore, variable primary side coolant inventory and resulting different swell level heights in U-tubes was investigated for provision of data for different heat transfer mechanisms and transition between the different flow patterns:

- Heat transfer in the SGs in presence of nitrogen, steam and liquid in the U-tubes

- Blocking of U-tubes by subcooled coolant slug with $\mathrm{N}_{2}$ enclosed

- Continuous und discontinuous single- or two-phase coolant transport in U-tubes (prospect of boron dilution)

Initial conditions of the test are illustrated in the figure 6 .

The test series comprises several changes of primary coolant inventory (PCI) with phases of steady-state conditions maintained by stable heat flow from primary to secondary side at constant primary pressure. Inventory was drained and replenished via lower plenum drain

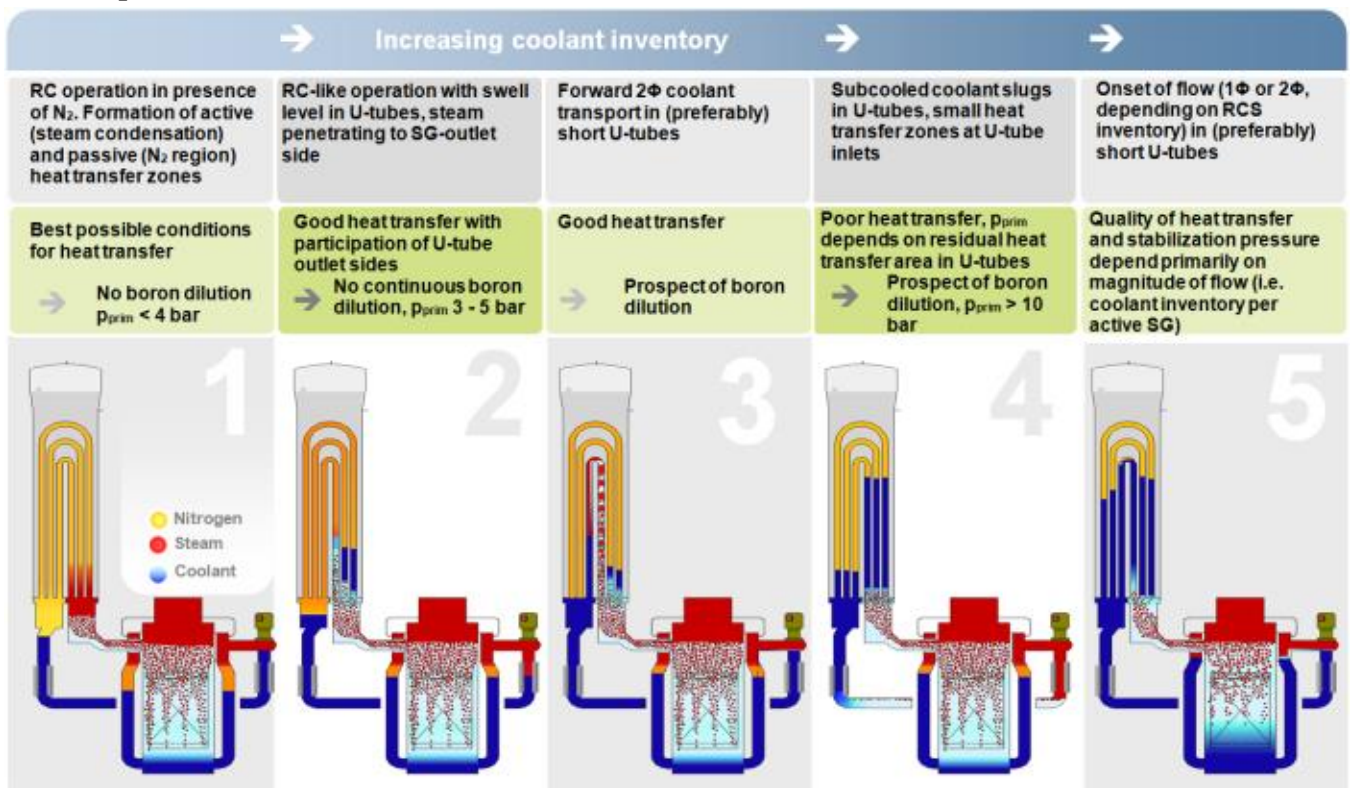

Fig. 5. Heat transfer in the SG as a function of the coolant inventory 
valve and a modified CVCS piping. In order to avoid a disturbance of the steam formation in the core as a consequence of exterior influence the liquid injection was directed to lower sections of downcomer tubes. The boundary conditions were adjusted to enable an in-depth analysis of the thermal hydraulic phenomena occurring in the SGs.

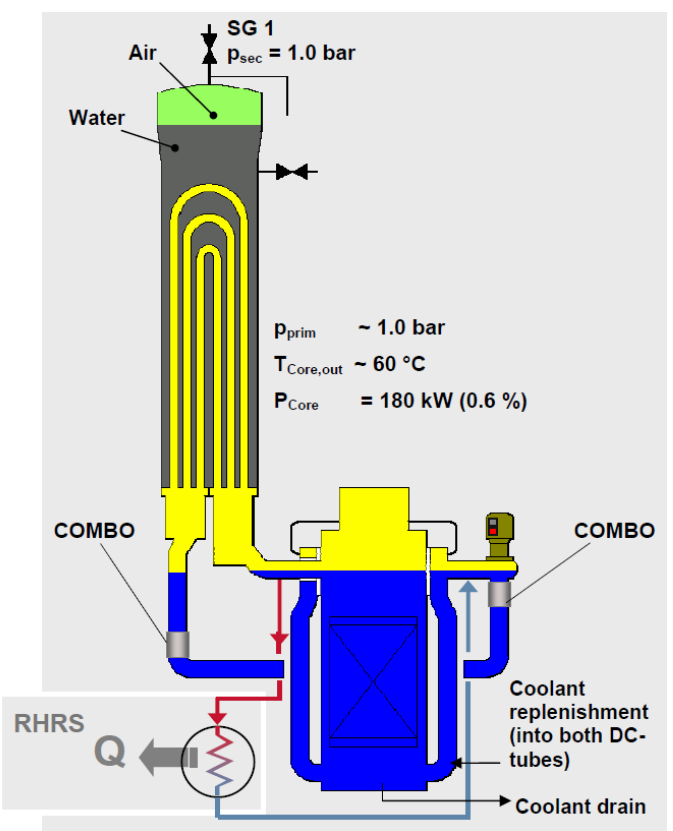

Fig. 6. Initial conditions of RHRS failure test

The whole run of single test lasted around 14 hours. During this time several steady state conditions were maintained as the coolant inventory was discharged and replenished (figure 5). Figure 7 shows conditions in the SG during overspilling of coolant in the shortest SG Utubes.

Overspilling of the coolant in the shortest U-tubes supports the natural circulation in the RCS and it increases the heat transfer. The temperature distribution in the long tubes indicates that in these conditions, the tubes are practically blocked.

The performed test campaign supported basic principles observed before and helped to formulate further conclusions related to heat transfer mechanisms. The obtained results are useful for the assessment of a full-size PWR thermal-hydraulic behavior. The main conclusions from the test campaign are:

- In case of RHRS failure and at least one SG operational, heat removal from the core to the secondary side is maintained, i.e. core cooling is assured in either case

- Pressure at the primary side stabilizes without the employment of any actions

In the scope of development of various heat transfer modes in the SG U-tubes, the following findings are applicable to full-scale PWR:

- Displacement of liquid water into the active SGs results in hindering the heat transfer as long as no overspilling and forward coolant transport into the outlet part of the U-tubes takes place

- Two active SGs provide a larger heat transfer area and reduce the pressure level required for stabilization

- Presence of two active SGs enables homogenous distribution of the coolant and it reduces the impact of injected liquid on the pressure gradient

- The expulsion of nitrogen from SG U-tubes is necessary for the onset of coolant transport, that supports heat removal to the secondary side

- Commencement of coolant transport - overspilling and regular natural circulation (figure 7) improves heat removal and consequently decreases the pressure at the primary side

The obtained test results were employed for the support of conclusions regarding NPP operation after loss of RHRS in the scope of primary side pressure and temperature stabilizing at moderate levels and prevention of boron dilution. Furthermore, the results are a valuable data base for code validation in the scope of various heat transfer mechanisms.

\subsection{Cool-down procedures under natural circulation and asymmetric boundary conditions (with isolated SGs)}

Cool-down under asymmetric boundary conditions can occur in the PWR after a feedwater or main steam line

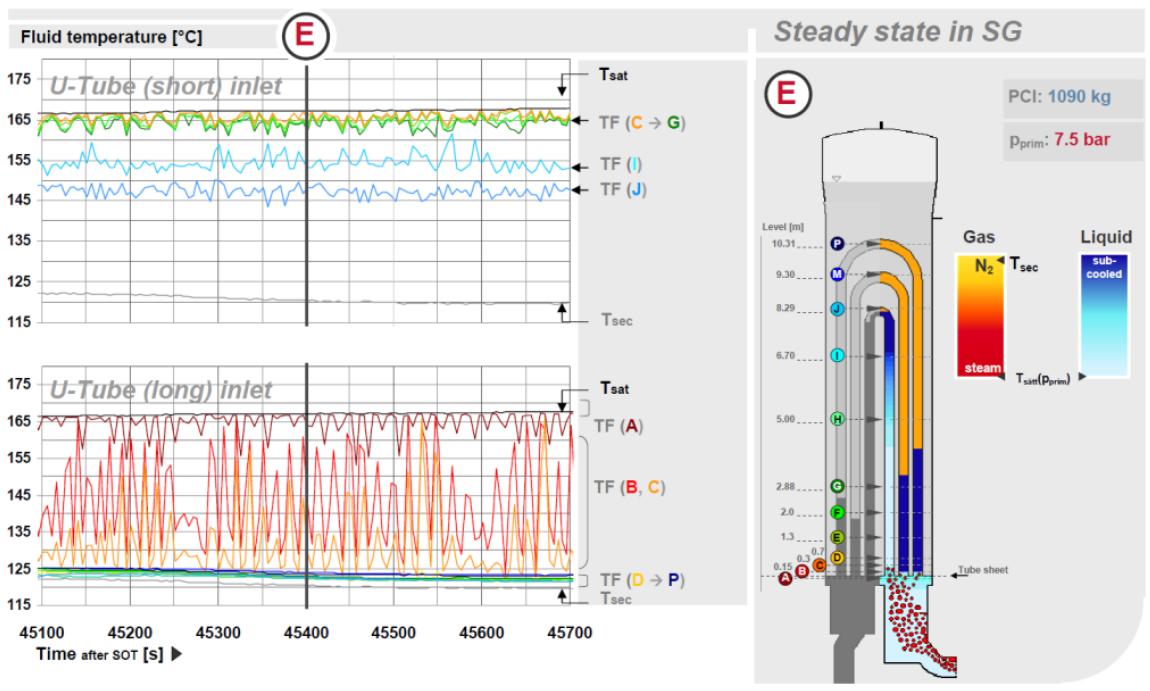

Fig. 7. Temperature profiles and flow conditions during overspilling in the shortest $U$-tubes 
break as well as in case of a SG U-tube leakage. During the test additional loss of offsite power was assumed, so the core was cooled under natural circulation conditions. After the postulated break or leakage at the secondary side the defective SG is heated up, liquid water inventory evaporates and the U-tubes are no longer covered with water which leads to hindering of the heat transfer. After isolating the feedwater and main steam lines, the temperatures at the inlet and outlet of broken SG U-tubes equalize and the driving force for natural circulation diminishes in the affected loop.

In the course of further cooling of the primary side through the intact SGs, the temperature in the primary circle can decrease below the temperature in the isolated SGs. As a result an opposing driving force occurs in the loops with isolated SGs leading to flow stagnation.

The stagnation can appear in two different ways. In the first one, the opposing driving force in the affected SG can become larger than the driving force resulting from heating of the fluid in the core. In the second case, saturation conditions and evaporation in the U-tubes can be reached as a result of pressure decrease at the primary side and simultaneous heating of the fluid in the U-tubes of the isolated SG.

In order to investigate the potential consequences and course of events under asymmetric plant cool-down and after LOOP several runs of the test were performed. Figure 8 illustrates the initial conditions of the test.

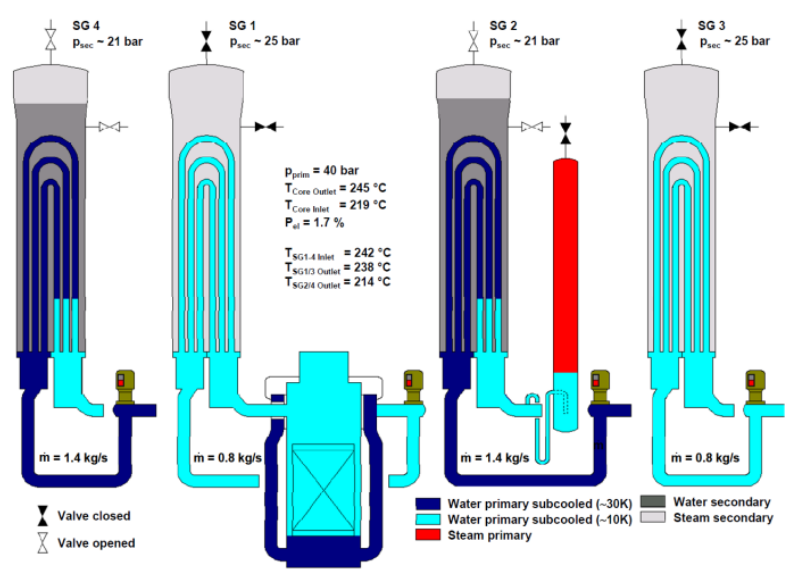

Fig. 8. Initial conditions of the cool-down procedure test

The particular emphasize was put on determination, whether $\mathrm{NC}$ can be maintained in the affected loops at continuous cool-down with $50 \mathrm{~K} / \mathrm{h}$ and after evaporation of water in the secondary side of isolated SGs assuming different accident management activities. In this context the NC behavior in the function of RPV outlet temperature and temperature difference between the inlet and outlet sides of the SG was of special interest. Furthermore, the opposing driving force in the isolated SGs as well as its consequences was investigated.

The first run of the test assumed additional injection of water from CVCS for pressure reduction. The second run was performed without this injection. The third run was dedicated for investigation, whether the $\mathrm{NC}$ can be maintained by stepwise cool-down.

The conclusions from all three runs can be summarized as follows:
- After evaporation of liquid water and isolation of two SGs (figure 9A), NC establishes in all loops. In the affected loops the flow is approximately two times lower than in the intact loops, where the $\mathrm{NC}$ can be maintained without cooling-down of the secondary side

- In the longer time perspective - ca. $1.5 \mathrm{~h}$ after LOOP - and for continuous cooling of the secondary side with $50 \mathrm{~K} / \mathrm{h}$ a complete stagnation of $\mathrm{NC}$ in the affected loops was observed (figure 10)

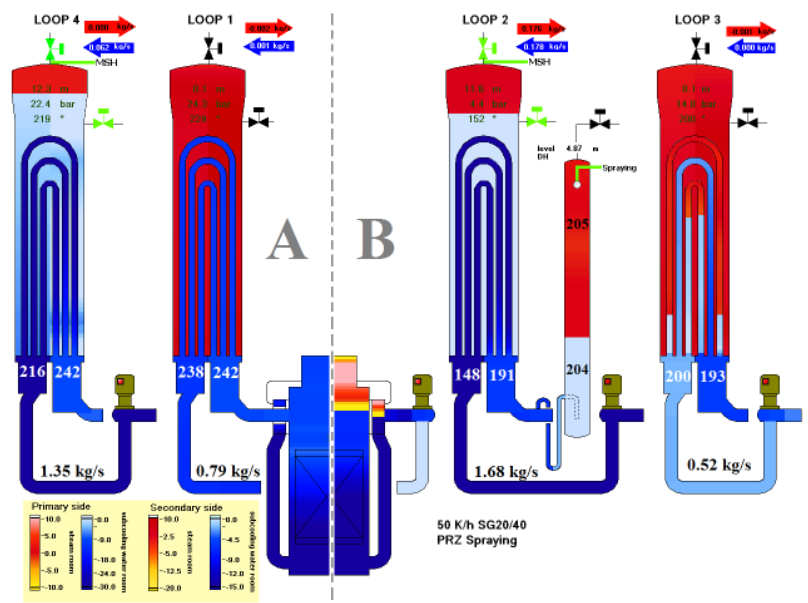

Fig. 9. Conditions during the test; A - after establishing of NC in all loops; $B$ - after lowering the primary side pressure

- In case of lowering the primary side pressure with the pressurizer spray of water from CVCS, evaporation of liquid in isolated SG U-tubes was observed although the subcooling of water at the core outlet was $10^{\circ} \mathrm{C}$ (figure 9B)

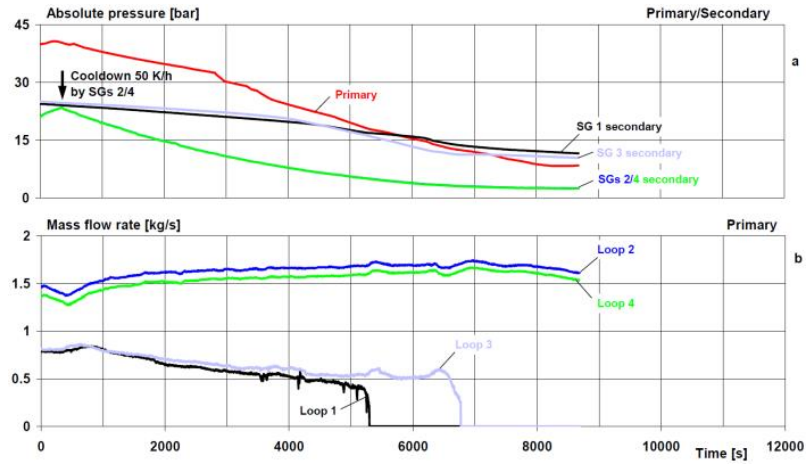

Fig. 10. Parameters evolution during cool-down under asymmetric boundary conditions test

- In the test run without pressurizer spraying much higher subcooling was maintained at the core outlet. This prevented boiling in the SG U-tubes but the flow stagnation in all or some of the U-tubes was still observed in the isolated SGs

- The stepwise cool-down resulted in maintaining the $\mathrm{NC}$ also in the isolated SGs. However, the test results revealed that in order to preserve $\mathrm{NC}$, the cooling must be conducted in a certain way, paying attention to the temperature difference between the inlet and outlet plenums. This temperature difference is a gauge for the driving force in the opposite direction and thus, an indicator of maintaining the $\mathrm{NC}$ in the loop (figure 11). 


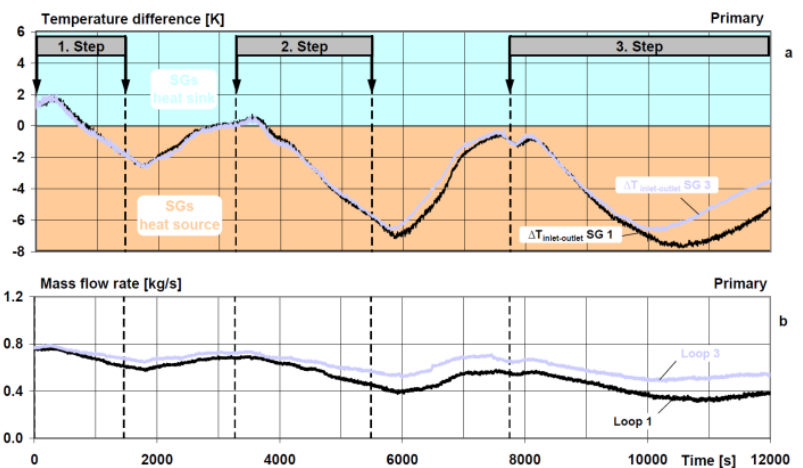

Fig. 11. M ass flows and temperature SG in-out temperature difference during the third run

\subsection{Influence of secondary side parameters on heat transfer under reflux condenser condition}

Reflux condenser (RC) mode is a cooling mechanism that can occur in SGs of PWRs in defined phases of SBLOCA only if safety injection systems are operating under reduced availability. In such scenario steam produced in the core flows through the HL to the SG Utubes and condenses. The condensed water flows due to gravity back to the RPV and supports cooling of the core. During the RC cooling mode counter current flow occurs in the SG tubes and in the HL since steam flows forward into the SG and liquid flaws backward to the RPV.

The performance of heat removal under RCconditions depends on the condensation mechanism. The film or dropwise condensation are the most effective ones and they contribute to emerging of low temperature differential between the primary and secondary sides, what in turn enables coupling both sides temperature and pressure levels facilitating the cool-down of the primary side.

During an analysis of LOCA scenarios in PWR a conservative assumption of additional failure, reduced availability or late initiation of safety injection system is postulated. Under these assumptions the most relevant parts of cooling procedure are presumed to be performed under RC-conditions. Therefore, the precise replication of the phenomenon is of central demand of thermalhydraulic codes employed by licensing authorities and expert organizations.

The procedure for dealing with the unlikely event of the LOCA scenario as set out in the operating manuals for PWRs is to reduce RCS pressure and temperature by cooling down the SGs secondary sides.

The test on the RC focuses on investigation of the influence of the secondary side boundary conditions (fill level, cool-down gradients) on heat removal from the primary to the secondary side in conditions resembling course of events of LOCA scenarios with lately initiated cool-down procedures. Therefore, rather than modeling a specific accident scenario, the test was designed as a parametric study to investigate how individual system parameters affect heat removal. Figure 12 shows the initial conditions of the test.

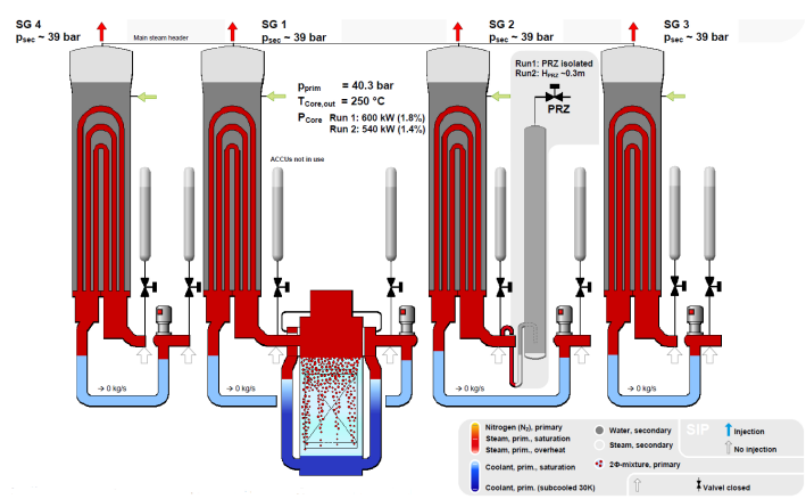

Fig. 12. Initial conditions of the RC conditions test

The variation of the parameters was distributed among two runs:

- Variation of secondary side fill levels

- Different cool-down gradients

The main objective of the test was to provide a data basis for thermal-hydraulic codes validation in the scope the following issues:

- Evolution of heat transfer and temperature difference

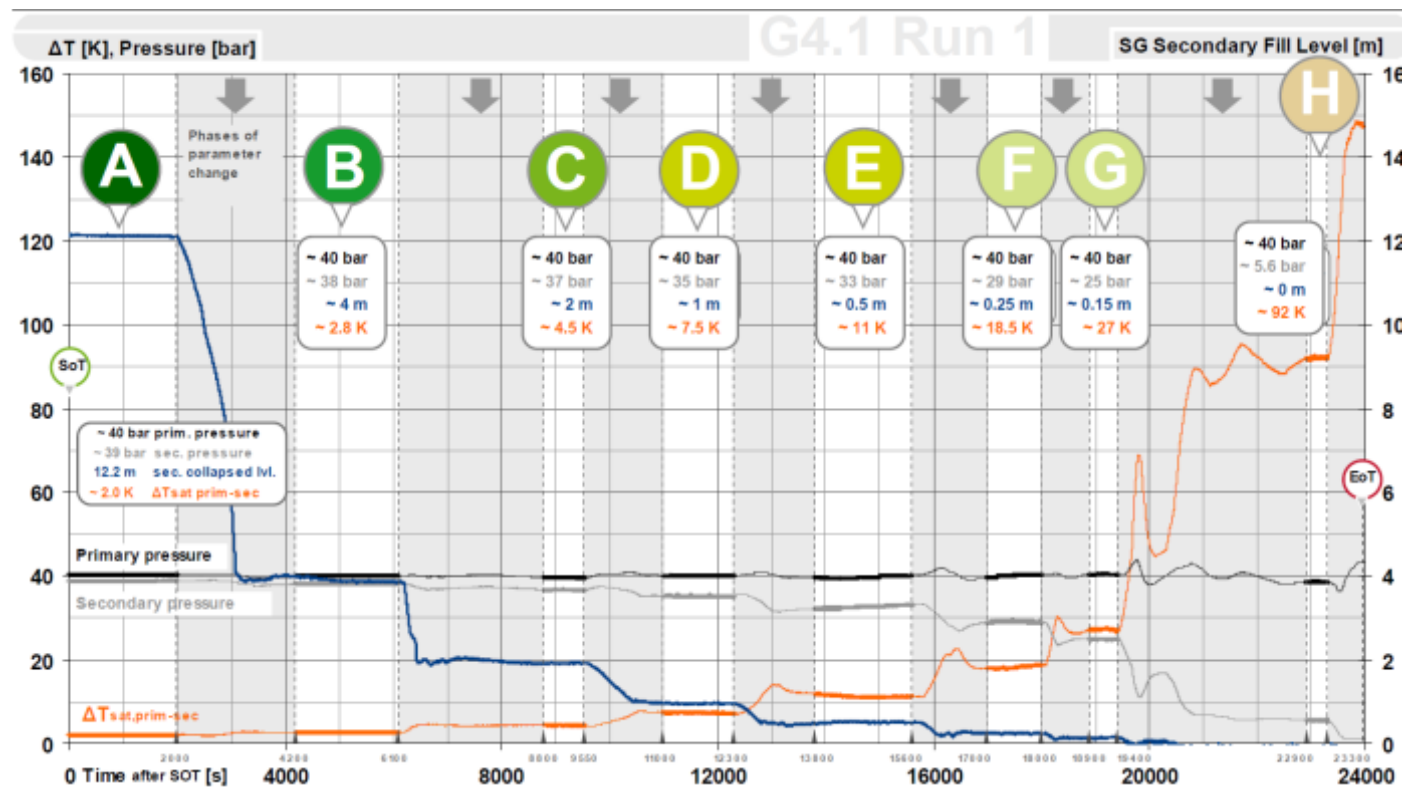

Fig. 13. RC mode test run 1 procedure and parameters evolution 
between the primary and secondary sides at different secondary side fill levels and during cool-down procedures under transient boundary conditions and different cool-down gradients

- Temperatures on secondary side during depressurization and injection of cold emergency feedwater in saturated water or saturated steam

- Occurrence and evolution of counter current flow limitation (CCFL) under RC conditions at different cool-down gradients

- Magnitude of displacement of coolant from the RPV into the SGs due to CCFL

In order to achieve the goals of the test scenario two runs of the experiment were conducted. The first run was dedicated to parameter study for investigation of heat removal decrease as a function of the secondary fill level. For this analysis multiple stepwise variations of SGs secondary side liquid water level with in-between periods $(\mathrm{A}-\mathrm{H})$ of steady state operation under $\mathrm{RC}$ conditions (figure 13).

The second run comprised a sequence of cool-down procedures through the secondary side from $250{ }^{\circ} \mathrm{C}$ at the core exit temperature and 40 bars at the primary side. The procedures were conducted with different cooldown gradients, i.e. 100, 250 and $470 \mathrm{~K} / \mathrm{h}$ (figure 14).

Across both test runs, the following significant test results may be summarized:

- Despite very low water level at the secondary side of the SGs, the heat transfer to the secondary side is preserved provided the SG feed is unbroken

- Reflux condenser operation mode assures a very effective heat removal. It requires only a low temperature difference between the primary and secondary sides to keep the pressures closely coupled

- During the cool-down sequences, substantial coolant displacements (from HLs towards SGs and in the RPV from the downcomer into the core region) occur. They do not however hinder core cooling even for $470 \mathrm{~K} / \mathrm{h}$ cool-down gradient

- CCFL was not observed in the SGs U-tubes for the pressure in the primary circuit over 10 bars for cooldown gradient of $100 \mathrm{~K} / \mathrm{h}$ and coolant inventories of approximately $40 \%$.

\section{PKL tests results benefits and implementation}

As the PKL is a worldwide unique test facility, it delivers solid data for a wide spectrum of implementation and it contributes to overall development of the nuclear industry - both in the context of human resources and in the field of general knowledge.

The major goal of all tests conducted at the PKL is supplying robust and comprehensive data for validation of thermal-hydraulic codes like RELAP, ATHLET, CATHARE and TRACE. Due to its large instrumentation density, the PKL has been substantially contributing to the development of the numerical representation of both, singular phenomena and integral systems. The computer codes verified against the PKL measurements are subsequently implemented for extrapolation of the results to the real PWRs. PKL project partners have been using the data base for validating their codes. During regular meetings within the PKL working group they can also provide their feedback and express proposals for the next tests. On the basis of simulations results presentations provided by various organizations from many countries implementing different codes, the conclusions for directions of further development are drawn. The working group gathered around the PKL projects became a unique platform of international debate on nuclear safety and for experiences exchange between organizations working on similar issues.

The program review group of the PKL projects has also grown into an important forum for other test facilities operators. Counterpart testing at other test rigs is a crucial aspect for investigation of various phenomena and scenarios replicated with different scaling principles. This in turn extends the knowledge and understanding in the scope of extrapolating results to full-scale PWRs. Thus, counterpart testing against other integral facilities such as LSTF, BETHSY, LOBI, PMK, PACTEL, ROCOM and JULIETTE was performed so far. Furthermore, counterpart testing against full-scale Upper Plenum Test Facility [15] (UPTF) proven that the results obtained at both facilities are complementary.

Another field, where the PKL results have been playing an important role since the construction of the

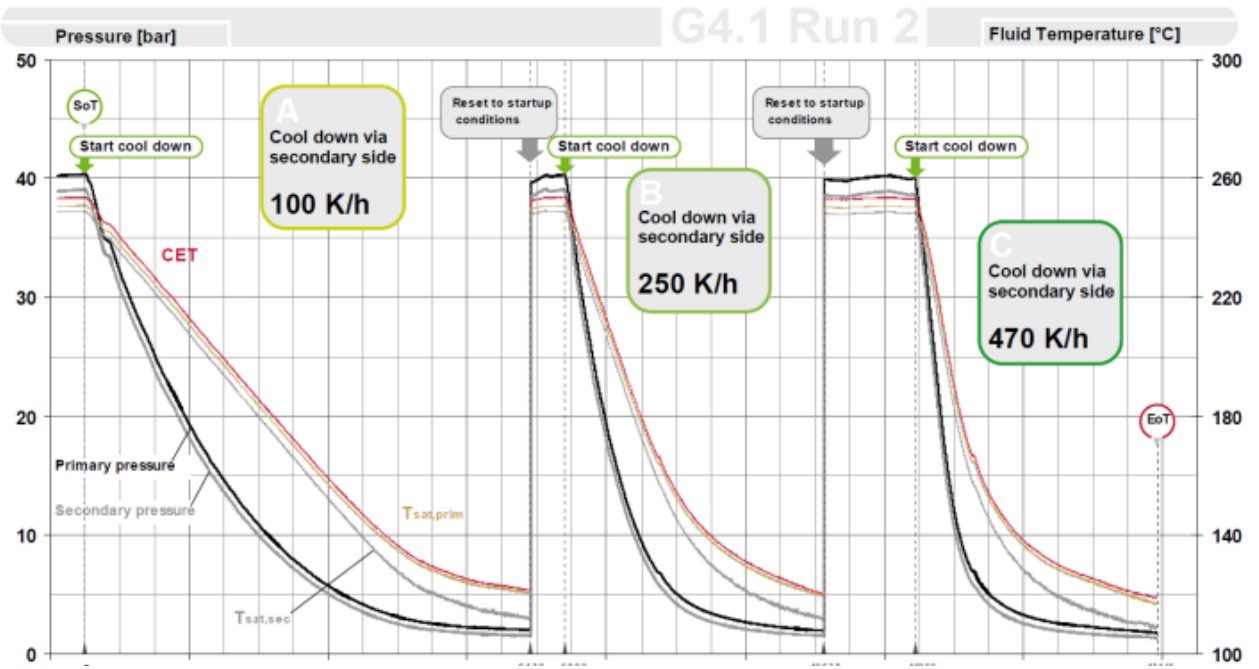

Fig. 14. RC mode test run 2 procedure and parameters evolution 
facility is addressing issues raised by licensing authorities. Over the years there have been many instances of contribution of the PKL to clarification of concerns related to emergencies and accidents procedures. Among the others, safety concerns in the scope of the influence of nitrogen on the heat transfer in the SGs raised by an authorized inspection agency were assuaged by means of the dedicated test.

Due to the fact, that the actual boron acid is used and detailed measurements of the local concentration are made in the PKL, the experiments performed to date delivered unique data base on PWR system behavior for boron dilution, boron precipitation and concentration at the core inlet. Further examples of addressing similar problems are described in [15].

PKL tests results are also used for verification and extension of operating manuals and cool-down procedures. Since the procedures are constantly improved and extended to cover all possible scenarios (even those of infinitesimal likelihood), the PKL outcomes largely contribute to inputs to the operating manuals.

The last but not least benefit of the PKL operation is the nuclear power plant operating personnel training. Theoretical trainings are conducted together with practical courses. The tests results provide graphic interpretation of the processes during operational transients and accidents and they are utilized to indicate the performance of the operator actions in a practical way.

\section{Conclusions and outlook}

PKL is a worldwide unique test facility replicating the entire primary side and the most relevant parts of the secondary side of PWR in the scale of $1: 1$ in height and $1: 145$ in volume and power. Since the very first test in 1977, over 200 integral experiments conducted at the PKL have contributed to a deeper understanding of highly complex phenomena occurring during operational transients and different accident scenarios. These tests led also to a better assessment of the countermeasures implemented for emergency control, development and extension of operating manuals and cool-down procedures as well as they provided unique and comprehensive data for codes validation.

Since 2001, the tests at PKL have been conducted in the frames of international cooperation within OECD/PKL projects. Up to now a number of parameter studies and cool-down procedures were examined and established assuming various scenarios, e.g.:

- Loss of RHRS under shut-down conditions

- Cool-down under natural circulation and asymmetric boundary conditions

- Influence of secondary side parameters on heat transfer under $\mathrm{RC}$ conditions

- Cold water transients following main steam line break

- Boron dilution events following SB-LOCA

- Boron precipitation following LB-LOCA

- Formation and behavior of upper head void during cool-down under NC conditions
- Effectiveness of secondary side depressurization, performance of the core exit temperature

- Effectiveness of accident management procedures during station black-out.

In the course of the currently conducted tests campaign the upper plenum and upper head of the PKL were significantly modified so that the facility did not only correspond to specific German-type PWR but also to American- and French-types which are nowadays widely constructed around the world. These modifications comprised installation of a new upper core plate, control rod guide assemblies, rod cluster control assemblies, upper support plate and the whole upper head vessel. Since the old configuration can be brought back, it is now possible to replicate any western-type PWR configuration.

The current PKL III i test campaign conducted in the frame of OECD/PKL-4 project will come to an end in the middle of 2020 . In order to address still open issues, prove the reliability and investigate the performance of innovative passive decay power removal systems, a new program will be proposed. The final content of the next project will be agreed with the project partners and it will aim at specific needs of involved organizations.

\section{References}

1. Mandl R., Brand B., Watzinger H., PKL reflood tests including end-of-blowdown, Proceedings of the 13th Water Reactor Safety Research Information Meeting, (1985).

2. Mandl R., Weiss P., PKL tests on energy transfer mechanisms during small-break LOCAs, Nuclear Safety Vol. 23 no. 2, pp. 146 - 158, (1982).

3. Umminger K., Kastner W., Mandl R., Weber P., Thermal hydraulic behavior of a PWR under beyond-design-basis accident conditions: conclusions from an experimental program in a 4loop test facility (PKL), Proceedings of the 2nd ASME-JSME Nuclear Engineering Joint Conference (ICONE '93) Vol. 1, pp. 409 - 416, (1993).

4. Umminger K., Mull T., Brand B., Integral effect tests in the PKL facility with international participation, Nuclear Engineering and Technology, Vol. 41, no. 6, pp. 765 - 774, (2009).

5. Umminger K., Dennhardt L., Schollenberger S., Integral Test Facility PKL: Experimental PWR Accident Investigation, Science and Technology of Nuclear Installations, Vol. 2012 (2012).

6. Mull T., Schoen B., Umminger K., Final Report of the PKL Experimental Programm within the OECD/SETH Project, Framatome ANP GmbH, (2004).

7. http://www.oecd-nea.org/jointproj/seth.html

8. https://www.oecdnea.org/tools/abstract/detail/csni2001

9. Umminger K., M ull T., Schoen B., Experiments on Boron Dilution in the Integral Test Facility $P K L$, Nureth-10: the Tenth International Topical Meeting on Nuclear Reactor Thermal Hydraulics, (2003).

10. Umminger K., Schoen B., Mull T., PKL Experiments on Loss of Residual Heat Removal 
under Shutdown Conditions in PWRs, 2006

International Concgress on Advances in Nuclear Power Plants (ICAAP '06), (2006).

11. https://www.oecd-nea.org/jointproj/pkl-2.html

12. https://www.oecd-nea.org/jointproj/pkl-3.html

13. https://www.oecd-nea.org/jointproj/pkl-4.html

14. Nuclear Energy A gency Committee on Nuclear Regulatory A ctivities, Loss of residual heat removal (RHR) while at mid-loop conditions corrective actions, NEA/CNRA/R(2006)4 (2006).

15. Liebert J., Brand B., Schwarz W., Sgarz G., Umminger $\mathrm{K}$., Results of UPTF and PKL research projects for PWR plant operation, VGB PowerTech, Vol. 79 no. 8, pp. 20 - 27, (1999). 